\title{
Correction to: Thyroid hormone therapy: past, present, and future
}

\section{David S. Cooper ${ }^{1,2} \cdot$ Leonidas H. Duntas ${ }^{1}$}

Published online: 13 November 2019

C Springer Science+Business Media, LLC, part of Springer Nature 2019

\section{Correction to: Endocrine}

https://doi.org/10.1007/s12020-019-02090-w

The original version of this article has unfortunately contain an error by adding quotation marks for the author details. The correct version is given below:

"Unfortunately, no satisfactory treatment is known." Sir William Osler, Principles and Practice of Medicine, 1892
The original article can be found online at https://doi.org/10.1007/ s12020-019-02090-w.

David S. Cooper

dscooper@jhmi.edu

1 Evgenideion Hospital, Unit of Endocrinology, Diabetes and Metabolism, National and Kapodistrian University of Athens, 20 Papadiamantopoulou Str., 11528 Athens, Greece

2 Division of Endocrinology, The Johns Hopkins University School of Medicine, 1830 East Monument St, Baltimore, MD 21287, USA “...that we can restore to life the hopeless victims of myxoedema is a triumph of experimental medicine... the results, as a rule, are most astoundingunparalleled by anything in the whole range of curative measures."

Sir William Osler, Principles and Practice of Medicine, 1898 